\title{
A Rare Case of Uterine Rupture Diagnosed In The
}

\section{Late Postpartum Period}

\author{
Onur Karaaslan $^{1 *}$, Ali Kolusari ${ }^{1}$, Pinar Kolusari ${ }^{2}$, Deniz Dirik ${ }^{1}$, Mehmet Sakinci $^{3}$, Erbil Karaman ${ }^{1}$ \\ ${ }^{1}$ Department of Gynecology and Obstetrics, Van Yüzüncü Yıl Üniversitesi, Van, Türkiye \\ ${ }^{2}$ Department of Anesthesiology and Reanimation, Van Education and Research Hospital, Van, Turkey \\ ${ }^{3}$ Department of Obstetrics and Gynecology, University of Akdeniz, Antalya, Turkey
}

\begin{abstract}
Obstetric hemorrhages are still the most common cause of maternal mortality worldwide (1). Uterine rupture, which could be included among the causes of postpartum bleeding, results in serious mortality and morbidity. Although scarless uterine rupture is extremely rare, it might be seen with an approximate frequency of $1 / 5700-1 / 20000$ in pregnancies (2-5). In general, it is diagnosed and treated in the early postpartum period as it usually presents symptoms at this very stage. A case of uterine rupture that was diagnosed and treated on the $28^{\text {th }}$ postpartum day was discussed in this case.
\end{abstract}

Key Words: Uterine rupture, late period, postpartum hemorrhage

\section{Case Report}

Our patient was 27 years old, gravida 2, parity 2 (normal vaginal delivery), and there was no history of abortion, curettage, chronic disease or previous operation. The patient had a normal vaginal delivery in 2018 and admitted to the hospital in 2019 , in the $39^{\text {th }}$ week of her second pregnancy, due to labor pain. Cervical dilatation was determined as $4-5 \mathrm{~cm}$ in vaginal examination and effacement was $60 \%$, these findings indicated her active labor and therefore she was admitted to the hospital. $1 \%$ oxytocin solution at the rate of $12 /$ min drops was used and a live baby girl was delivered by normal vaginal route without any problem 5 hours after hospitalization. The patient was discharged from hospital on the $1^{\text {st }}$ day of postpartum as she had normal hemogram values and vitals. The patient was applied to the emergency service as her bleeding from the abondan suddenly started on the $28^{\text {th }}$ day of postpartum, she was curetted as vaginal ultrasonography indicated possibility of rest placenta and she was transferred to our clinic due to continuing bleeding after $1 \mathrm{~g}$ of tranexamic acid application and placement of bacri balloon within the uterine cavity. In the performed ultrasonography the bacri balloon was seen in the uterine cavity and a $7 \mathrm{~cm}$ hematoma was observed in the right side of the uterus. Pelvic MRI was performed due to suspicion of arterio venous malformation (AVM), and there was no appearance compatible with AVM in pelvic MRI. After the removal of the Bakri balloon, the patient's bleeding started again and thus diagnostic laparotomy was performed. In laparotomy, a full thickness rupture area of approximately $5-6 \mathrm{~cm}$ along the right lateral wall of the uterus and a perforation area of approximately $0.5 \mathrm{~cm}$ in the fundus of the uterus were observed. After the repair of rupture and perforation area a drain was placed in the abdomen and the operation was terminated.

\section{Discussion}

Postpartum hemorrhage might also be classified as primary and secondary (6). While those occurring in the first 24 hours of postpartum are classified as primary, the bleedings those are occurring after 24 hours of postpartum to $12^{\text {th }}$ week is classified as secondary (7). The primary causes are postpartum atonia and genital trauma and secondary causes include rest placenta, infection, and arteriovenous malformations (6).

Scarless uterine rupture can be caused by trauma or congenital diseases that impair the myometrium. Motor vehicle accidents and obstetric maneuvers (eg internal or external

*Corresponding Author: Onur Karaaslan, Department of Obstetrics and Gynecology, Van Yüzüncü Yıl University, Faculty of Medicine, Van, Turkey

E-mail: onurkaraaslan62@gmail.com, Phone: +90(543) 8345363

ORCID ID: Onur Karaaslan: 0000-0002-4599-1173, Ali Kolusari: 0000-0001-5678-8958, Pinar Turgut: 0000-0002-3081-9960, Deniz Dirik: 0000-0002-5169-4052, Mehmet Sakinci: 0000-0001-5074-0005, Erbil Karaman: 0000-0003-1058-2748 


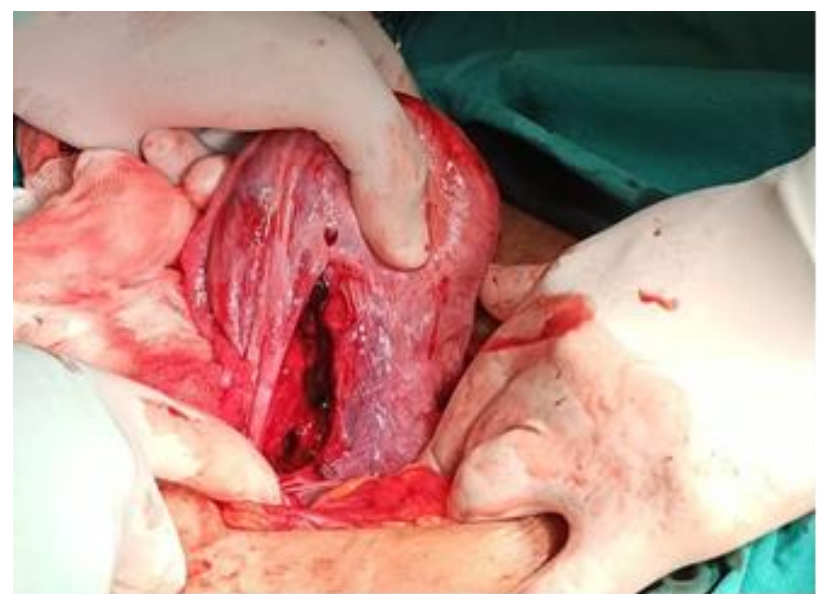

Fig. 1. Right Paramatreium Rupture Area

cephalic version) can be considered as trauma sources. Myometrium may be weakened by a congenital disorder such as Ehlers-Danlos type IV, prolonged labor and use of uterotonic drugs (8-13). High parity, uterine anomalies, late maternal age, dystocia, macrosomia, multiple pregnancy, abnormal placenta (e.g. placenta accreta, increta, or percreata), short conception interval, and cerclage history (14-17) can be counted as risk factors for the rupture of scarless uterus. In this case, the use of uterotonic agents and pregnancy in less than 2 year time interval are considered as risk factors. Hypotension, tachycardia, and abdominal pain may be observed depending on fetal heart rate changes, rupture size and abdominal bleeding amount (14). Uterine sensitiveness, changes in the shape of the uterus, and cessation of contractions may be seen depending on the rupture (18-20). Vaginal bleeding may not be seen even though the presence of abdominal bleeding within the abdomen, vaginal bleeding is generally seen in the cases when the lasered cervix and vaginal walls are accompanied as well. Hematuria may accompany when the bladder involves.

A definite diagnosis can be made during laparotomy performed because of suspecting fetal distress or hemodynamic instability of the mother in intrapartum ruptures and vaginal bleeding or hemodynamic instability of the mother in postpartum ruptures. Therefore, a high level of suspicion is required to be able to make a diagnosis. The structure of the uterus and bleeding into the abdomen can be evaluated with transvaginal ultrasound in the postpartum suspected cases (15). Although more than $90 \%$ of the cases occur in the anterior wall in the lower uterine segment, it may also occur in the corpus, cervix, vaginal walls, uterine interface, and parametrium (18).

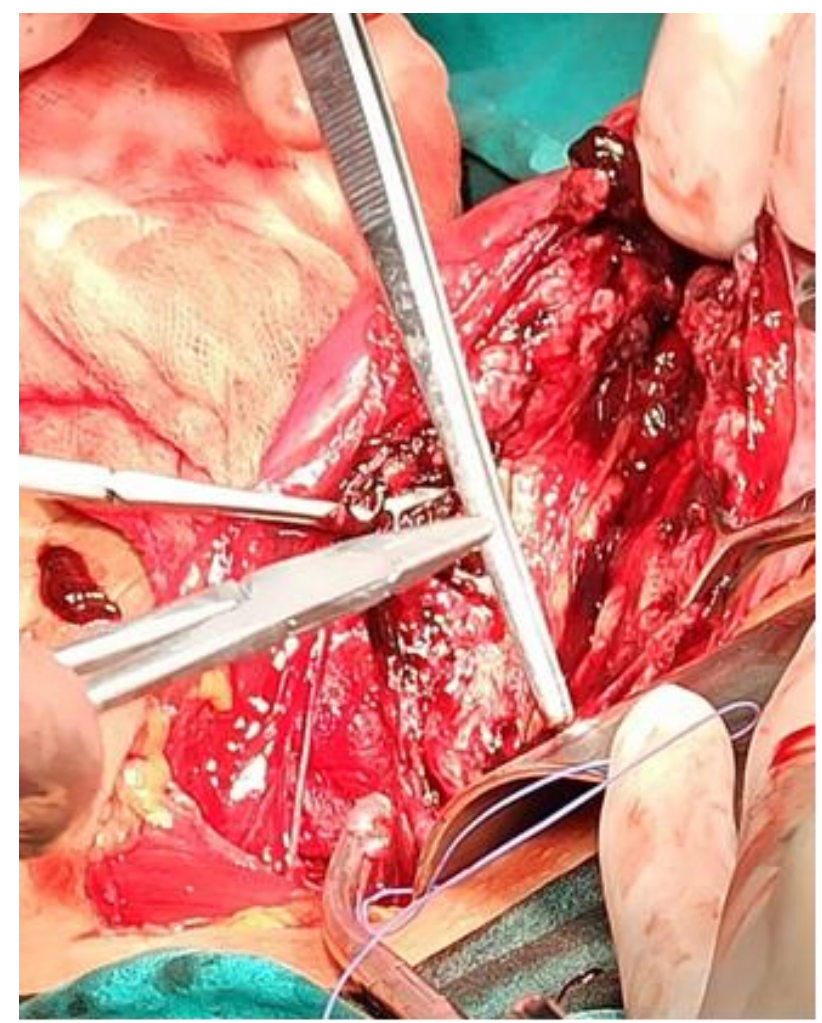

Fig. $2.7 \mathrm{~cm}$ Rupture Area Extending Into The Vagina

Uterine ruptures have a serious mortality and morbidity depending on the location of the rupture, its size, the time of diagnosis and intervention (21-23). Therefore, it is usually necessary to diagnose and treat uterine ruptures in the early period. In this case, the rupture area was observed widely in laparotomy, however it is thought that the existing rupture might be expanded due to the application of bacri balloon. Since there are no large vessels in the rupture area, it is thought that there were no findings in the early period. As can be seen in this case, uterine rupture should be considered in patients who apply to the clinics with bleeding in the late postpartum period and have signs of bleeding on ultrasound.

\section{References}

1. Say L, Chou D, Gemmill A, et al. Global causes of maternal death: a WHO systematic analysis. Lancet Glob Health 2014; 2: 323.

2. Dow M, Wax JR, Pinette MG, et al. Thirdtrimester uterine rupture without previous cesarean: a case series and review of the literature. Am J Perinatol 2009; 26: 739.

3. Porreco RP, Clark SL, Belfort MA, et al. The changing specter of uterine rupture. Am J Obstet Gynecol 2009; 200:269.e1. 
4. Miller DA, Goodwin TM, Gherman RB, Paul RH. Intrapartum rupture of the unscarred uterus. Obstet Gynecol 1997; 89: 671.

5. Zwart JJ, Richters JM, Ory F, et al. Uterine rupture in The Netherlands: a nationwide population-based cohort study. BJOG 2009; 116 : 1069.

6. WHO recommendations for the prevention and treatment of postpartum haemorrhage: 1 . Postpartum hemorrhage - prevention and control. 2. Postpartum hemorrhage - therapy. 3. Obstetric labor complications. 4. Guideline. I. World Health Organization 2012.

7. Prevention and Management of Postpartum Haemorrhage: Green-top Guideline No. 52. BJOG 2017; 124: 106-149.

8. Pepin M, Schwarze U, Superti-Furga A, Byers PH. Clinical and genetic features of Ehlers-Danlos syndrome type IV, the vascular type. N Engl J Med 2000; 342: 673.

9. Walsh CA, Reardon W, Foley ME. Unexplained prelabor uterine rupture in a term primigravida. Obstet Gynecol 2007; 109: 455.

10. Taylor DJ, Wilcox I, Russell JK. EhlersDanlos syndrome during pregnancy: a case report and review of the literature. Obstet Gynecol Surv 1981; 36: 277.

11. Rudd NL, Nimrod C, Holbrook KA, Byers $\mathrm{PH}$. Pregnancy complications in type IV Ehlers-Danlos Syndrome. Lancet 1983; 1: 50.

12. Sakr R, Berkane $N$, Barranger $E$, et al. Unscarred uterine rupture--case report and literature review. Clin Exp Obstet Gynecol 2007; 34: 190.

13. Khabbaz AY, Usta IM, El-Hajj MI, et al. Rupture of an unscarred uterus with misoprostol induction: case report and review of the literature. J Matern Fetal Med 2001; 10: 141.
14. Gibbins KJ, Weber T, Holmgren CM, et al. Maternal and fetal morbidity associated with uterine rupture of the unscarred uterus. Am J Obstet Gynecol 2015; 213: 382.e1.

15. Walsh CA, Baxi LV. Rupture of the primigravid uterus: a review of the literature. Obstet Gynecol Surv 2007; 62: 327.

16. LeMaire WJ, Louisy C, Dalessandri K, Muschenheim F. Placenta percreta with spontaneous rupture of an unscarred uterus in the second trimester. Obstet Gynecol 2001; 98: 927.

17. Tarney CM, Whitecar P, Sewell M, et al. Rupture of an unscarred uterus in a quadruplet pregnancy. Obstet Gynecol 2013; 121: 483.

18. Ofir K, Sheiner E, Levy A, et al. Uterine rupture: differences between a scarred and an unscarred uterus. Am J Obstet Gynecol 2004; 191: 425

19. Ozdemir I, Yucel N, Yucel O. Rupture of the pregnant uterus: a 9-year review. Arch Gynecol Obstet 2005; 272: 229.

20. Markou GA, Muray JM, Poncelet C. Risk factors and symptoms associated with maternal and neonatal complications in women with uterine rupture. A 16 years multicentric experience. Eur J Obstet Gynecol Reprod Biol 2017; 217: 126.

21. Chauhan SP, Martin JN Jr, Henrichs CE, et al. Maternal and perinatal complications with uterine rupture in 142,075 patients who attempted vaginal birth after cesarean delivery: A review of the literature. Am J Obstet Gynecol 2003; 189: 408.

22. Kwee A, Bots ML, Visser GH, Bruinse HW. Uterine rupture and its complications in the Netherlands: a prospective study. Eur J Obstet Gynecol Reprod Biol 2006; 128: 257.

23. Phelan JP, Korst LM, Martin GI. Causation-fetal brain injury and uterine rupture. Clin Perinatol 2007; 34: 409. 